\title{
Good fences are key to sustainable pasture management and harmonious pastoral society of Merak and Sakteng in Bhutan
}

\author{
Sonam Wangdi iD and Nawang Norbu
}

\begin{abstract}
There is limited knowledge about the traditional tsamdro management practice, particularly the building of walls and fences by the pastoral nomads of Merak and Sakteng. Conflicts related to tsamdro resource access are not a new phenomenon in Bhutanese pastoral communities. In the recent past, as an adaptive response to external economic, political, social and ecological changes, the tsamdro was nationalized. This change in policies brought a host of challenges specifically in managing the existing and building new tsamdro border structures.

The objective of the study was to elucidate the motives and purposes behind the building of tsamdro structures, and to explore the historical development, significance and future of yak farming by Brokpas. We used a semi-structured questionnaire and face-to-face interview for collecting both quantitative and qualitative data from 40 yak herders opportunistically selected from both Merak and Sakteng gewogs, village block, refers to a group of villages in Bhutan Trashigang district.

The study revealed that tsamdro border structures were primarily built to ensure harmony within the Brokpa society by reducing conflicts caused by livestock trespassing, but structures indirectly assisted in tsamdro management. The structures were one of the encashable family assets passed across generations and played a critical role in shaping the socio-economic developments of Brokpas. Though the tsamdro was nationalized, the Brokpas still continue to hold tsamdro ownership rights and build new tsamdro border structures to protect their livelihood. The contradiction between the government's policy and Brokpas' livelihood pattern will have a detrimental effect on both the social harmony of nomadic herders and the traditional tsamdro management practice. We suggest the government develop nomadic-centered policies that encourage tsamdro resource sharing within the Brokpa communities. Socio-economic development incentives are required to address the trespassing conflicts.
\end{abstract}

Keywords: Tsamdro, Border structure, Yak, Conflict, Brokpa, Livelihood

\section{Introduction}

Pastoralism is one of the primary sources of livelihood for mountain and rural communities throughout the world (Bagchi et al. 2004; Kreutzmann 2012; Ning et al. 2016; Wangchuk et al. 2013, 2013; Wiener et al. 2003), particularly in developing countries. In Asia, transhumant pastoralism is the mainstay of subsistence economies in temperate and alpine zones (Bagchi et al. 2004). In the Himalaya mountain regions, millions of pastoralists depend on the natural pasture resources. Pastoralism is a subsistence living pattern

\footnotetext{
* Correspondence: swangdi@uwice.gov.bt

Ugyen Wangchuck Institute for Conservation and Environmental Research, Department of Forests and Park Services, Ministry of Agriculture and Forests, Lamai Goempa, Bumthang, Bhutan
}

through livestock herding (Blench 2001; IFAD 2009). Yaks and yak-cattle hybrids are the dominant livestock species raised by the Himalayan mountain communities.

As in many countries across the Himalaya, pastoralism is an integral component of the agricultural farming system in the Himalayan Kingdom of Bhutan. Almost 70\% of Bhutan's population depends on livestock and crops for their sustenance (WCD 2013). Yak herding is the predominant pastoral practice in all mountain communities of Bhutan. Currently, the Kingdom holds 1,156 yak herding households, with over 49,617 yaks including $d z o-d z o m^{1}$ that contribute about $4 \%$ to the livestock products generated in the country (DoL 2016). Pastoral yak herding is sparsely distributed across the northern 
belt of Bhutan over 34 sub-districts in ten districts. The livelihood of highlanders not only depends on yaks but also relies heavily on the availability and prosperity of pasture land (tsamdro) (Chettri 2008; Chand 2017), which plays a critical role in supporting the yaks.

\section{Potential catalysts for tsamdro resource use conflicts}

The traditional transhumance pattern in Bhutan has a unique characteristic of tsamdro (Figure 1) resource-sharing system; multiple households, villages and districts gain grazing access to the same tsamdro during different seasons (Moktan et al. 2008). Sometimes, the grazing ownership is seasonal because of overlapping users (Ura 2002). For instance, the patch of tsamdro belongs to the herdsman of yak in winter and a cattle herdsman in summer. This creates a complex tsamdro resource-sharing mechanism between the high- and low-altitude pastoralists. Consequently, the tsamdro lacks a sufficient period for natural regeneration of forage, thereby decreasing the forage productivity and leading to grazing rights conflicts (Wangchuk et al. 2014).

An inadequate tsamdro area may be one of the potential causes for illegal grazing conflicts among the herders (Brokpa brok= pasture; $\mathrm{pa}=$ inhabitants). Of the total area of 500198.6653067847 ha of registered tsamdro in the country, Merak and Sakteng constitute over 6\% and this provides a grazing area of over 1.21406 ha per ani$\mathrm{mal}$ in both the (a village block consisting of a group of villages) gewogs (Table 1). However, the actual grazeable area may be less than half, if the shrub cover, unusable areas and forage grazed by wild animals are deducted (Gyeltshen et al. 2010; Wangchuk et al. 2013, 2013). Merak shares the border with Arunachal Pradesh (India) in its east. Phongme, Radi, and Shongphu in the west and Kangpara gewog of Trashigang district and Lauri gewog
Table 1 Basic statistic and livestock population of Merak and Sakteng gewogs

\begin{tabular}{lll}
\hline Category & Merak & Sakteng \\
\hline Gewog (village block) area $\left(\mathrm{km}^{2}\right)$ & 867.7 & 910.9 \\
Households (number) & 280 & 386 \\
Population (inhabitants) & 2,160 & 2,313 \\
Tsamdro area (hectares) & 16503.282833 ha & 17320.1650834 ha \\
Livestock (number) & & \\
$\quad$ Yak & 2,963 & 4,002 \\
Dzo-dzom & 4,553 & 4,179 \\
Cattle & 4,547 & 1,671 \\
$\quad$ Equine & 733 & 1,138 \\
Sheep & 1,851 & 1,196 \\
Goat & 72 & 98 \\
Total livestock & 14,719 & 12,284 \\
\hline
\end{tabular}

Source: Livestock Statistic (DoL 2016)

of Samdrup Jongkhar district in south. Sakteng shares the geographical boundary with Arunachal Pradesh in its north and east and Phongme in the west. Both the gewogs have pastureland conflicts with their neighbouring gewogs particularly the Merak with Phongme and Radi gewogs (Figure 2). Thus, the expansion of tsamdro area is pushed to the limit.

Recently, the tsamdro conflict within the herders' community has become a serious issue (Dorji 2013). For instance, on October 31, 2015, the Kuensel, a state newspaper, reported that Sakteng police investigated seven people involved in a clash over a tsamdro resource dispute. Various dispute litigations were prosecuted in the district court within the Brokpa community. Today, apparently, the intensity of conflict seems to be settled, but such strife

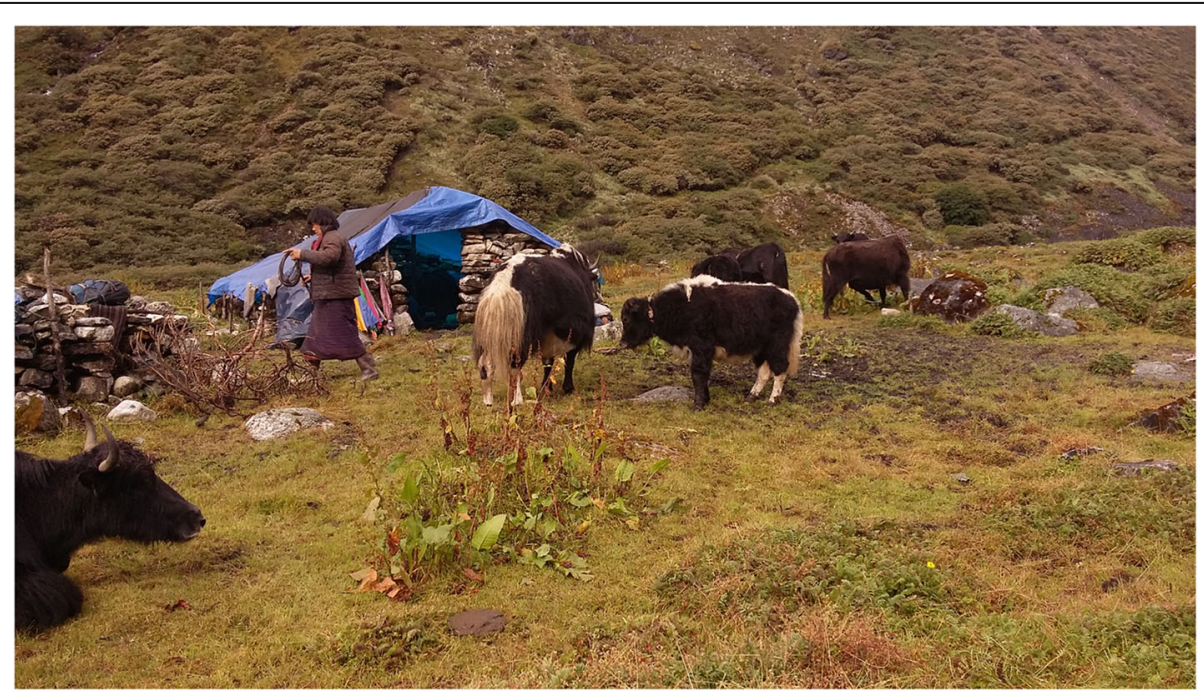

Figure 1 Tsamdro is refered to a native grazing land/pastureland/grassland 


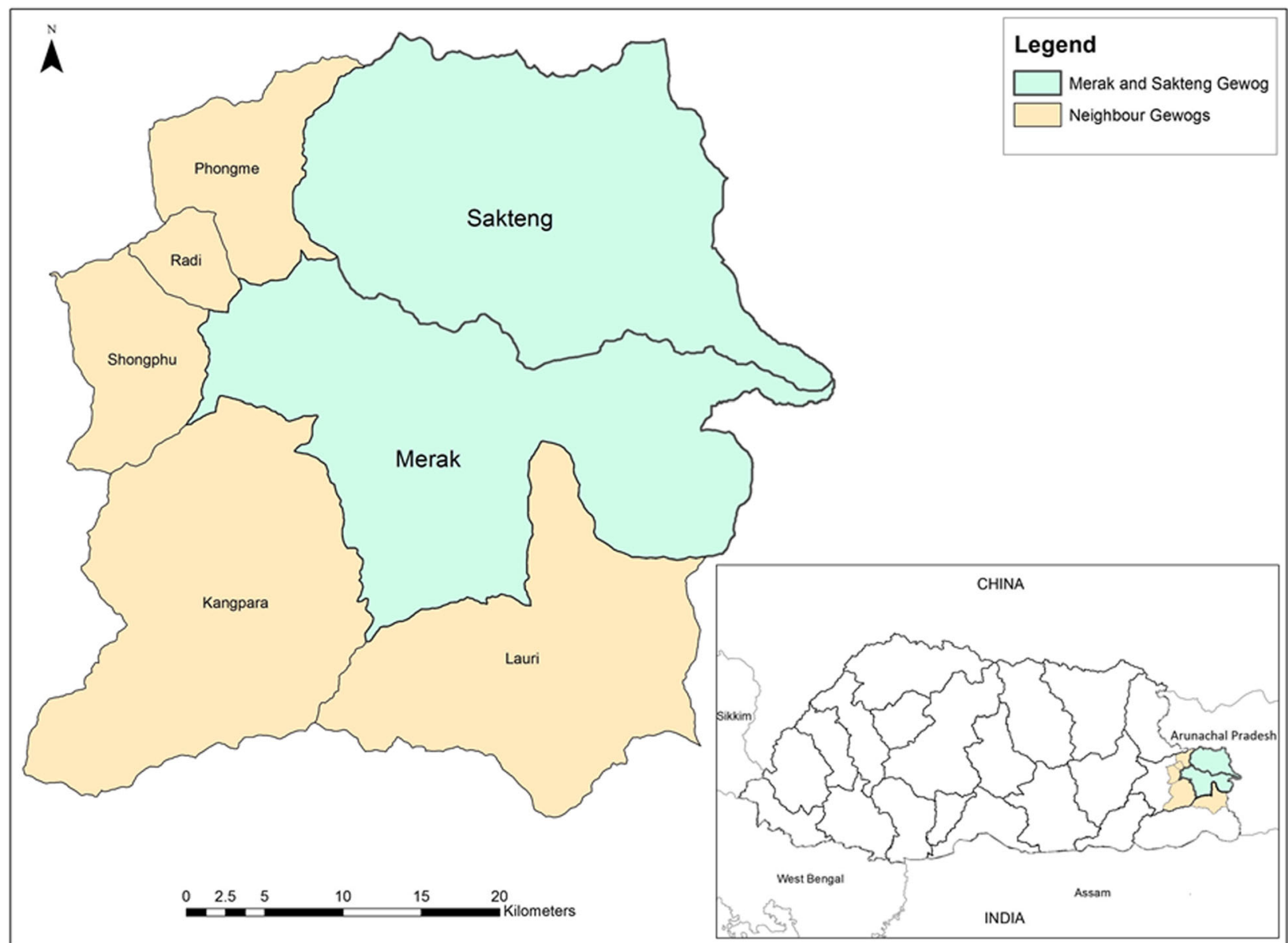

Figure $\mathbf{2}$ The study area and its geographical boundary with adjacent gewogs

may easily unfold in the future due to various factors. For instance, the gradual shrinkage of tsamdro size is due to an increase growth of unpalatable species such as Juniper and Rhododendron (Dorji 2013; Gyamtsho 2002; Tshering 2013; Ura 1993; Wangchuk et al. 2013, 2013; Wiener et al. 2003). A strong environmental conservation policy such as restriction of burning pastureland increases grazing pressure on open grassland, and this heavily grazed area is susceptible to erosion and gully formation (Gyeltshen et al. 2010; Namgay et al. 2013; Ning et al. 2016). Typically, a household's tsamdro was divided among the children into smaller grasslands, and also, the birth of every cow exacerbates a decrease of grazing area for a family.

\section{Tsamdro border structures and development}

To address the trespassing conflicts, herders have devised various techniques such as guarding their tsamdro round the clock by residing at the key strategic migratory routes and implementing frequent monitoring. Gradually, minuscule semi-permanent wooden gates (gaags see Figure 3) were installed at the key migratory routes and along traditional footpaths, which helped to minimize illegal grazing.
Communal grazing lands have had wooden gates installed to prevent livestock grazing prior to the community's agreed entry dateline. In the past, communities appointed a gatekeeper (gaag sungpa) for about two months before the agreed dateline to guard the common pastures (Chophyel 2009). The gatekeepers were paid in the form of butter and cheese by the communities. This traditional system of appointing gatekeepers has now disappeared from the Brokpa society, but inevitably, they still continue to rely on the gates to safeguard their tsamdro from illegal grazing.

Since the gates have proven to be the most effective mechanism in preventing illegal grazing, the Brokpas embarked on building various short length stone walls and wooden fences at the main routes along the tsamdro border. These structures were built since time immemorial (Chophyel 2009), and as old as the history of Merak and Sakteng. Since then, the Brokpas have continued to build more walls and fences, sharing the labour cost between the tsamdro owners with whom they share the border. Consequently, over the generations, they have built extensive border structures, the stone walls in summer pastureland and wooden fences in winter grazing land, but not in all the pasturelands. 


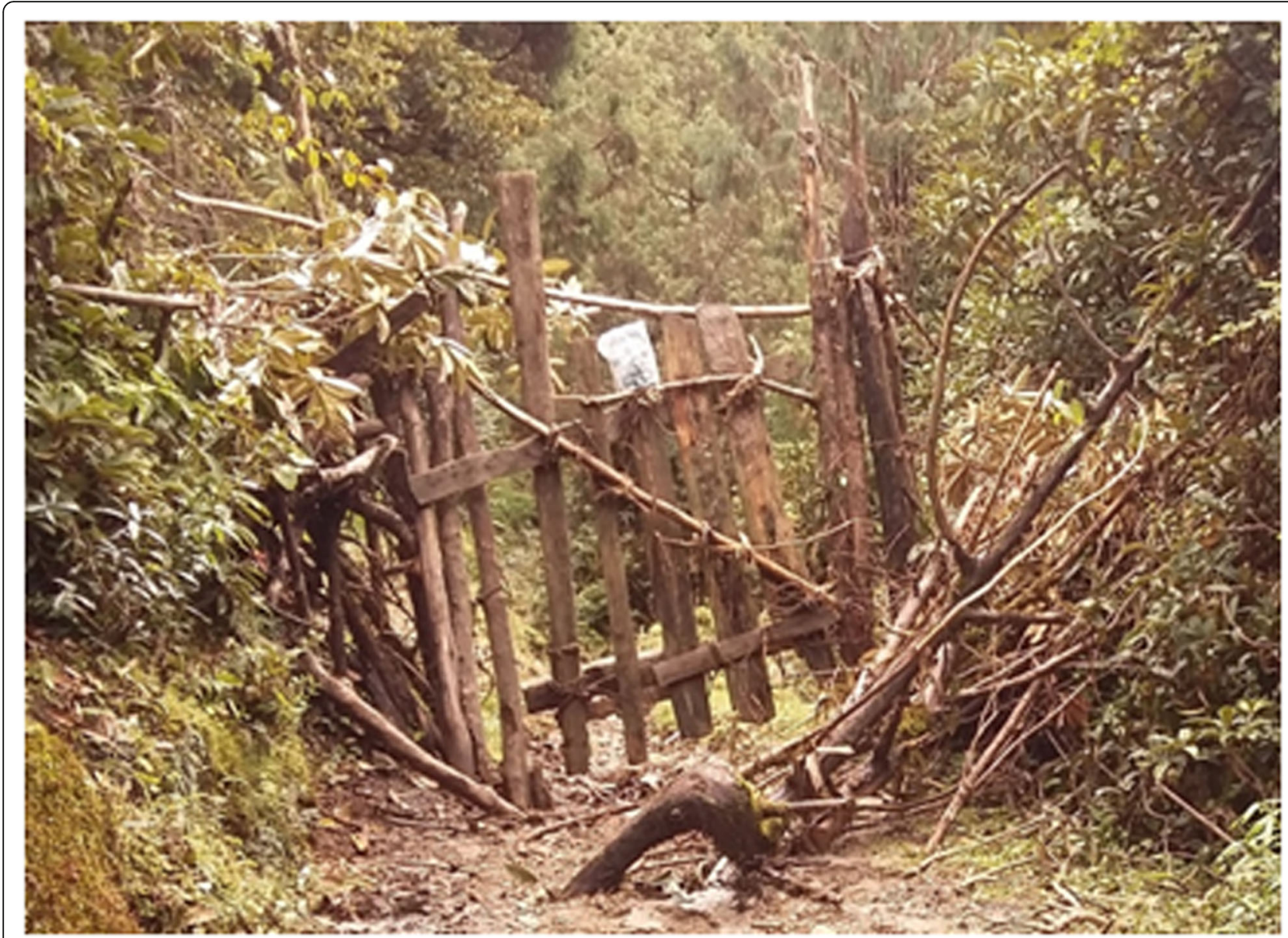

Figure 3 Gaag on Merak-Sakteng trail

Currently, new border structures are still being built at the porous tsamdro border connecting with the old structures. Some of the walls spanned and waved through majestic mountains, treacherous hills, lush meadows and dense Rhododendron shrubs (see Figure 4).

\section{Legality of tsamdro border structures}

Around the world, highlanders face increasing threats to their livelihood from internal and external economic, political, social and ecological changes (de Haan 1993; Derville and Bonnemaire, 2010; Fratkin and Mearns, 2003; Namgay et al. 2017; Nori and Davies, 2007; Wiener et al. 2003) and Bhutan is no exception. In recent years, the change of policy to delete tsamdro ownership rights had posed a significant threat to the livelihood of highlanders, particularly the Brokpas. Among various tsamdro-related policies, the Forest and Nature Conservation Rules of Bhutan 2006 and the Land Act 2007 seem to have a direct adverse impact on the building and usage of tsamdro border structures.

The Land Act of 1979, heavily drawn from the 1957 Thrimzhung Chhenmo (Ura 2002) which is the supreme law of the land, has not levied the annual tsamdro tax obliquely planned for the nationalization. Consequently, the National Assembly, the highest decision-making body, passed the Land Act 2007, which states that "all tsamdro rights maintained in the Thram [Land Register] prior to enactment of this Act shall be deleted from the Thram [...] shall be reverted and maintained as the Government land in Thromde or the Government Reserved Forests(GRF) land in rural areas" (NLC 2007, p. 55). Accordingly, the records of tsamdro- and community-registered lands were all deleted and nationalized. However, the government intends to re-distribute the tsamdro resources by leasing out to the livestock holders with certain fees for sustainable management and operation. Meanwhile, the Forest and Nature Conservation Rules 2006 enforces that "construction or placement of any permanent or temporary structure, fences, [...]are restricted within the GRF (DoF 2006, 15)". From this perspective, the Brokpas have no rights over the tsamdro and are restricted from building any structures within the pasture land.

These policies were applied to livestock transhumant practitioners and tsamdro holders across the nation, but 


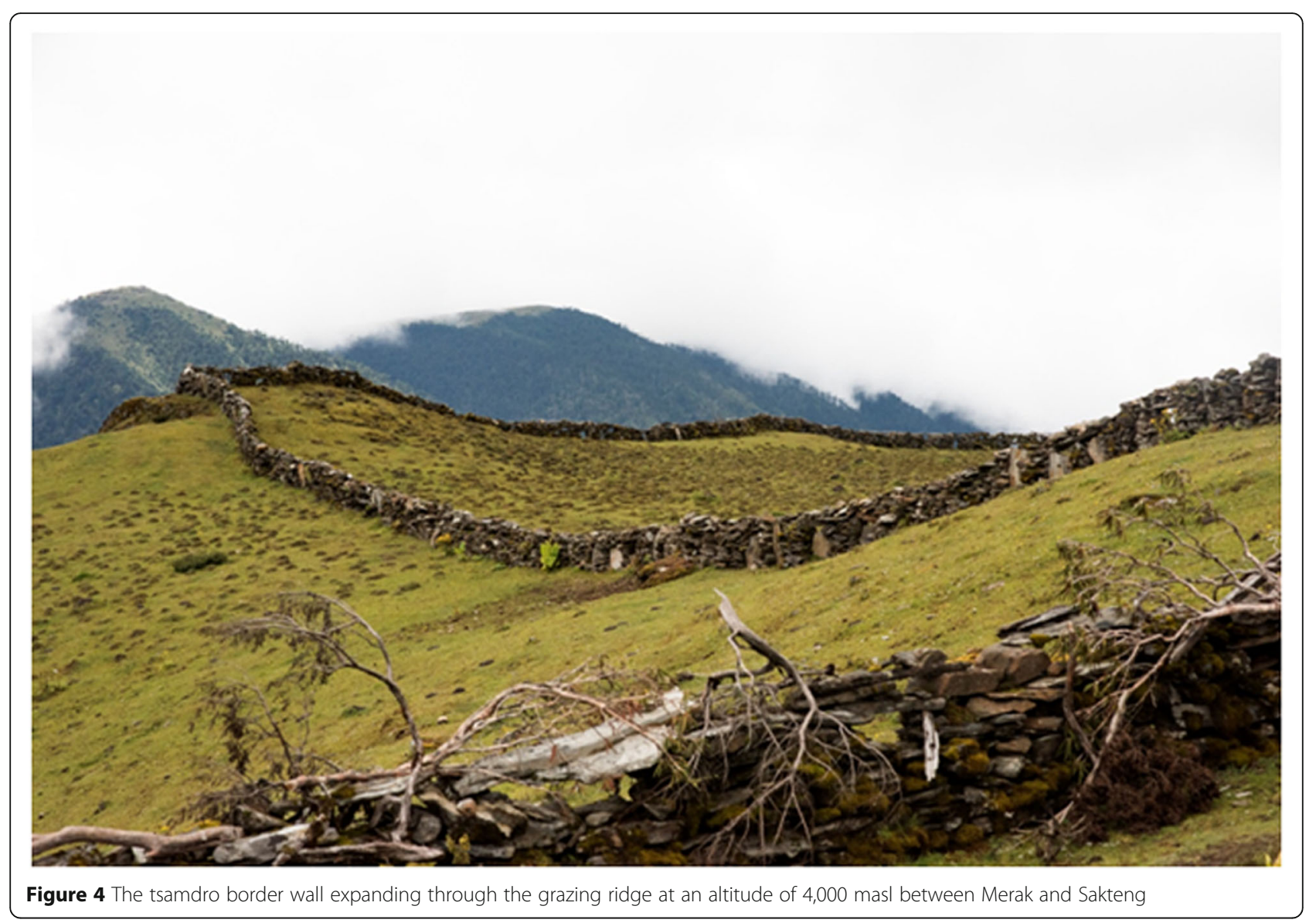

the intensity of negative implications is felt relatively differently by the tsamdro holders, depending on their current livelihood patterns. Given the nature of fertile land located within the proximity of modern development activities, the low-altitude pastoralists have other options provided by the agricultural farming and industrial economic opportunities. The mountain communities of central (Trongsa and Bhumthang) and western (Wangdue and Gasa) districts are heavily dependent on the harvest of Ophiocordycep sinensis; thereby, yak farming - erstwhile the primary source of livelihood - is now secondary. However, for Brokpas, yak farming is the only viable income source.

Various studies have been conducted to understand the tsamdro and its complex operational processes and associated challenges. However, we lack comprehensive understanding of the tsamdro border structures, particularly the walls and fences and their significance in supporting the livelihood of Brokpas. As a result of the tsamdro nationalization, the border structures built over generations - once an acclaimed family asset - are now pushed to the edge and may gradually disappear from the Brokpa society. Our study was aimed at elucidating the motives and purposes behind the building of tsamdro border structures, and it explores the historical development, significance and future of yak farming by Brokpas.

\section{Study area}

The study was conducted in Merak and Sakteng gewogs stretching from latitude of 27017.84 to $27018.51 \mathrm{~N}$ and longitude 91050.76 to $91052.12 \mathrm{E}$, under Trashigang district in eastern Bhutan (Figure 2). The gewogs have an area of $1,778.6 \mathrm{~km}^{2}$ and consist of 666 households with a total population of 4,473 . The people of these gewogs are commonly called Brokpa, semi-nomadic inhabitants of Merak and Sakteng, synonymous with herdsman, shepherds or people who herd cattle.The households have a total of 15,697 yaks including calves, dzo-dzom, heifers, breeding_bulls, bulls (DoL 2016). The majority of residents depend exclusively on yaks to meet their basic needs in the form of milk and milk product such as butter, cheese, fermented cheese and clothing materials (Moktan et al. 2008; Wangdi 2016). They also generate cash incomes through the sale of yak products and occasionally live yaks and meat for 
their socio-economic development (Chophyel 2009; Joshi 2009; Gyamtsho 2000). Today, the Brokpashave switched to settled lifestyles as semi-nomadic highlanders, partially depending on sedentary farming (Ura 1993) and collecting non-wood forest products like Paris polyphyla and Exidia sp.

Merak and Sakteng gewogs were selected for the study because they were established as pasture-based villages (Ura 2002), where conventional crop farming was not feasible due to extreme climatic conditions. These regions are one of the high-altitude pastoral communities with yak herding as the primary source of livelihood and more than $90 \%$ of households dependent on tsamdro (Joshi 2009). Consequently, over the generations, the herders have constructed walls and fences to guard their tsamdro resources from illegal grazing.

The highlands of Merak and Sakteng not only are distinctive in livelihood strategies but also have a unique culture and tradition, including their dress and spoken language. The landscape is characterized by rugged mountains, steep slopes and deeply incised valleys. The pasture regimes of Brokpas are located between 2,500 and 4,500 masl, and vegetation cover ranges from broadleaf forests to alpine zones. Temperature varies according to elevation, of snow in the winter with extreme cold, and abundant rain in summer. The Merak area has been recently connected with a farm road, while Sakteng still lacks road network accessibility.

\section{Methods}

A total of 40 households were interviewed, 20 each from Merak and Sakteng gewogs, who are fully dependent on yak rearing as their livelihood. A semistructured questionnaire was used for data collection from the selected yak farming households. The semistructured questionnaire and interview provided more in-depth interviewing, that offered freedom to both interviewer and respondents to follow new leads but also served as a general guide to cover a set of topics. The questionnaire ensured collection of reliable, comparable quality data within a minimum interview duration for nomadic herders. Semi-structured interviews serve best when we cannot interview the respondents for the second time, due to their nature of living and livelihood pattern.

The interviews were conducted face-to-face by interviewers because most of the nomadic herders are illiterate and inaccessible by telecommunications to acquire the required information. All the data were collected by the primary author, co-author and research assistants from the Ugyen Wangchuck Institute for Conservation and Environmental Research. The data were collected in October 2016, qualitatively analyzed and presented descriptively in this paper.

\section{Results and discussion}

\section{Background information of the respondents}

Out of 40 interviewees, $67 \%$ were male and $33 \%$ were female. The majority of respondents (92\%) were uneducated, and $8 \%$ had attended primary education. More than half $(62 \%)$ of respondents were herders, and $38 \%$ were both farmers and herders. The average herd size was 52 yak heads per household, while the median number of yaks was 43.5 and $50 \%$ of households entirely depended only on yak rearing while others relied on both yak and cattle farming for their livelihood. Most of the respondents (68\%) had been herders for more than 20 years, and almost the entire respondents (98\%) said they would like to continue as semi-nomadic herders.

\section{Historical characteristics and significance of border structures}

Of the 40 households, slightly more than half $(52 \% ; n=21)$ of the households owned tsamdro border structures. Of the 21 households, the majority of respondents $(81 \%$; $N=17$ ) believed the walls were built by their forefathers and were over hundred years old (Figure 5). This signified that the border structures are a gift, wisdom and legacy emanated from the soul of the Brokpas' ancestors. The walls were built without any mortar using a dry-stack technique, and their wall-building crafts were passed down through families. Field observation: This is observed during the field visit to various pasturelands of Merak and Sakteng. The wall building-process portrayed the resilience of their nomadic system, which has the potential to secure livelihoods for future generations. The walls are important structural and architectural features that need to be preserved and protected, but now, the fate of these historic walls lies in the hands of government. This conclusion reflects the opinions of the interviewees, as well as our own observations and interpretations from our fieldwork.

Slightly more than a quarter $(29 \% ; n=6)$ of the households' walls spanned over more than $4 \mathrm{~km}$, while $24 \%(n=5)$ respondents' walls stretched for 3-4 km (Figure 5). The walls were built to 45 to $50 \mathrm{~cm}$ width and 150 to $200 \mathrm{~cm}$ in height. Initially, most of these structures were built along the main livestock migratory routes at different locations. These walls were later joined together and formed a long tsamdro border wall (Figure 5). These semi-permanent structures are maintained and improved annually or whenever deemed necessary. The walls were structurally designed with a rectangular brick size opening in every alternative block to prevent the walls being dismantled by strong gusty wind and also served as an efficient use of stones. The design of the wall demonstrates the sustainable use of natural resources which has long been integrated and 


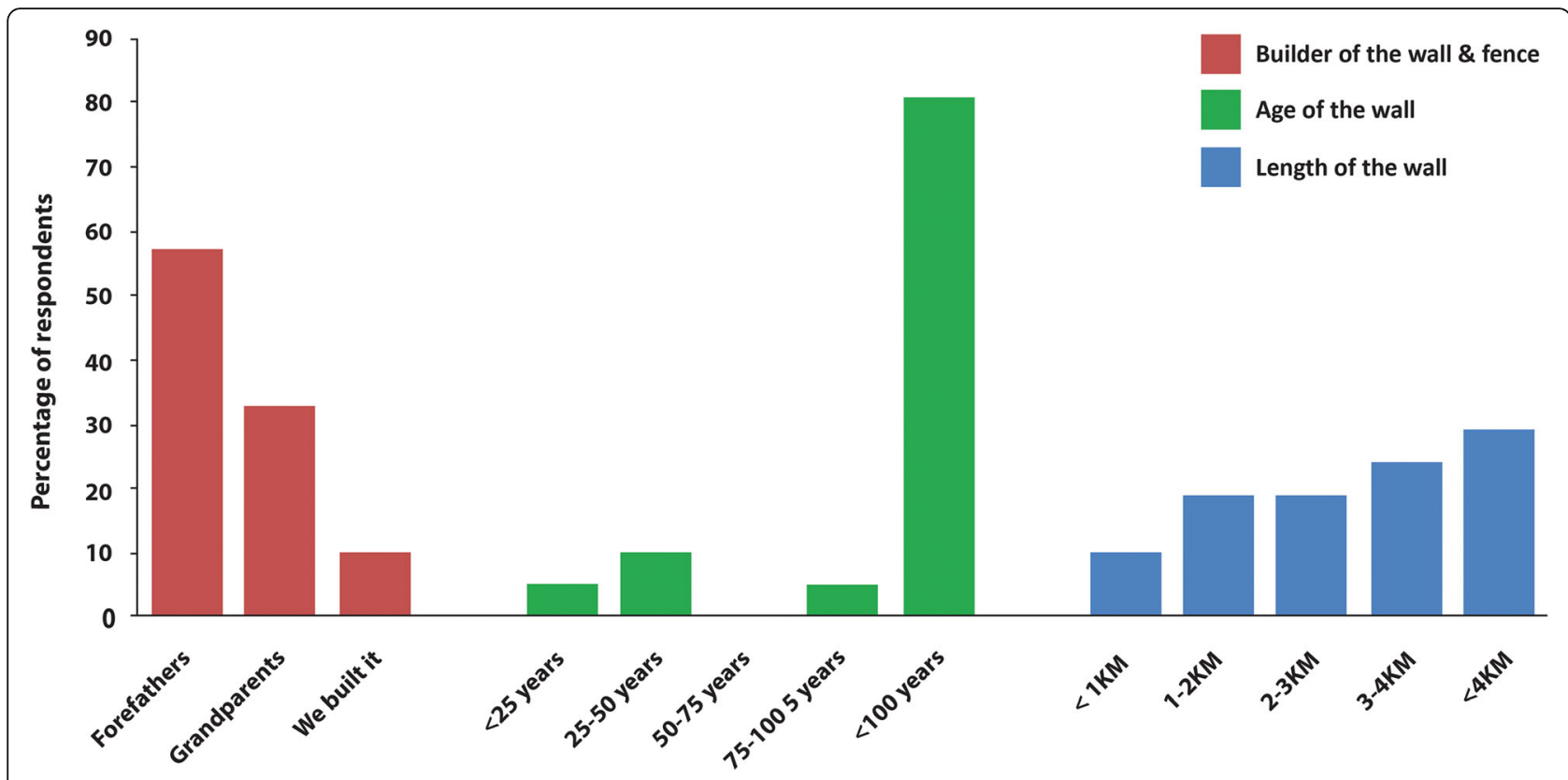

Figure 5 Historical characteristics of the wall

practiced by Brokpas to conserve their high-altitude resources. These staunch wall structures played an important role in tsamdro management practices.

The presence of nomadic herders on the edge of Bhutan's northern belt protects the mountain resources from any potential external exploitations and encroachments, safeguarding border security (MOAF 2017; Namgay et al. 2017; Wangdi 2016). Otherwise, the government would have to allocate huge resources to secure and protect these mountain natural resources from external intruders. Without herders and their pastoral activities such as building stone and wooden fences, these vast high-altitude areas would remain uninhabited and underutilized (Gyeltshen et al. 2010). These structures shaped the socio-economic livelihood of Brokpas while holistically and sustainably utilizing the mountain resources at dispersed locations.

\section{Purpose and management of the tsamdro border structures}

The majority $(76 \% ; n=16)$ of interviewees who have border structures believed that the primary purpose of the walls and fences was to keep their livestock in, as much as to prevent the trespassing by neighbours' animals (Figure 6). This has minimized grazing conflicts within herders' communities and reinstated peace and tranquility for Brokpa society. These structures also indirectly helped to demarcate the tsamdro boundary (Figure 7) and created conditions for tsamdro resource management. For instance, the walls and fences protect the tsamdro from being grazed by wild animals during the plant regeneration period (Chophyel 2009) in the early spring season while yaks are still at lower altitude. Herders carry out forage production activities within the fenced tsamdro area, such as extraction of stones and unpalatable plants, generating more space for meadows to grow. They also amassed yak and cowpats in a particular spot as animals avoid grazing grasses growing on their own dung. The collected sundried dung is used as fuel, thus helping to reduce the consumption of high-altitude forest resources.

Almost half of the respondents $(48 \% ; n=10)$ renovated the tsamdro border structures whenever deemed necessary, while $38 \%(n=8)$ of the respondents conducted annual maintenance (Figure 6). The frequency of renovation differed from one household to another, depending on the need for maintenance. Border structures were designed to be semi-permanent and required a huge one-time investment of time, labour and resources, so thereafter the maintenance cost was minimal. Unless the structures required large-scale renovation, a patch of wall or fence damaged due to trespassing or strong wind is restored by herders while herding the yaks. Forest resources particularly the stones available within the tsamdro area are efficiently utilized to either build new or renovate old damaged walls.

The execution of current tsamdro re-distribution system merits the government to innovate new measures to reduce the trespassing conflicts among herders. Policymakers must formulate Brokpa people-centered approaches to plans and policies, in order to bring social developments which may minimize the pressure on livestock rearing, thereby reducing conflicts. Different Brokpa communities must collaborate together to build 

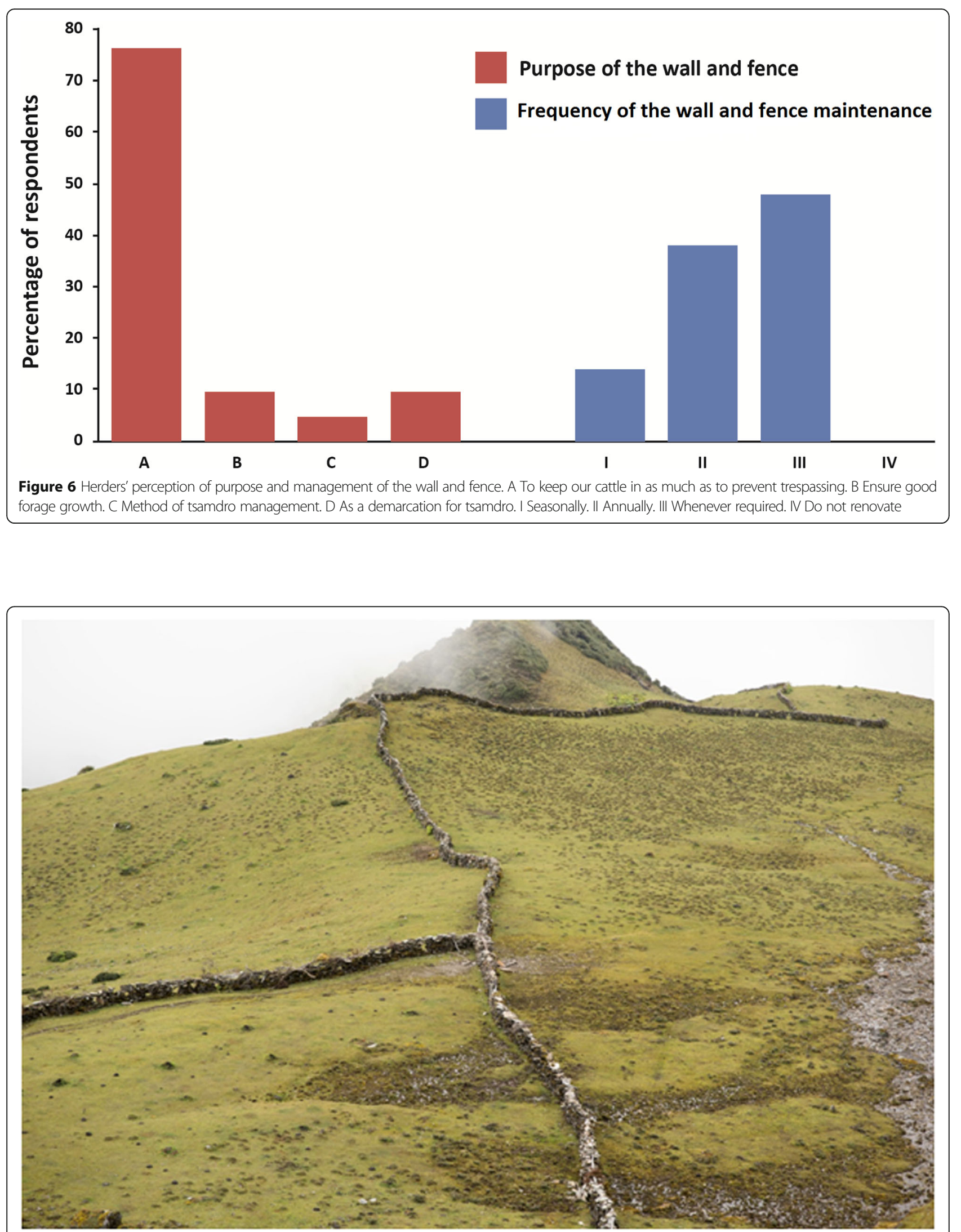

Figure $\mathbf{7}$ Tsamdro walls demarcating the pastureland boundary between three households in Merak 
the necessary knowledge and capacities to mitigate and adapt to grazing conflicts and inadequate grazing area. For this, the government must support the strengthening of these collaborations, and encourage new partnerships within communities and individual families. Unless the communities are cooperatively empowered to collaborate and be part of the Brokpa societal development process, effectively addressing tsamdro grazing conflicts, an individual family's livelihood priority may supersede such change. Consequently, the current new system introduced by the government may be confronted with the same old challenge. And yet again, the Brokpas may need to apply the archaic solution of building stone walls and wooden fences.

\section{The current challenges and future trend of the border structures}

Among various challenges, almost half $(48 \% ; n=10)$ of the respondents reported that the permit restrictions by forestry officials on collecting stones and poles are one of the main impediments to renovating and building new structures (Figure 8). After the enactment of Land Act 2007, the government has the right to impose permit restrictions and also penalize illegal extractions as per the Forest and Nature Conservation Act 1995 to conserve mountain biodiversity and ensure sustainability. Inadequate border building materials such as stones and poles within the vicinity of tsamdro are likely to be one of the challenges in the future. However, currently, the Land Act 2007 has an immediate negative impact on Brokpas' livelihood, particularly on the management of tsamdro border structures. The policy has pushed the Brokpas' economic development to the edge and also discouraged the continuation of yak herding. The new policy is a bottleneck for alleviating poverty for rural citizens, particularly the transhumant nomads, although the government pledges to improve the livelihood of rural people. The government could restrict the building of new tsamdro border structures, but granting permits to renovate the existing structures. This would support brokpas in securing their livelihood, while assisting the government to move towards sustainability.

In terms of conservation and sustainability, the change of policies on tsamdro ownership rights without deeper understanding of the daily livelihoods of pastoralists in the country (Namgay et al. 2014), particularly the Brokpas, is illegitimate and may cause an adverse effect. The policy undermined the time, energy and resources invested in building the border structures, and also ignored the value of these structures in contributing to harmonizing Brokpa society. However, the government intends to lease the same tsamdro to the previous rights holders (NLC 2007), which may potentially boost a sense of rights over their structures. Through such entrustment, the existing tsamdro border structures may continue to serve their purpose and shore-up the Brokpas' flagging economy.

Through the nationalization process, the government intends to correct the imbalance in tsamdro resource access (Chophyel 2009; Gyeltshen et al. 2010; Namgay et al. 2017).

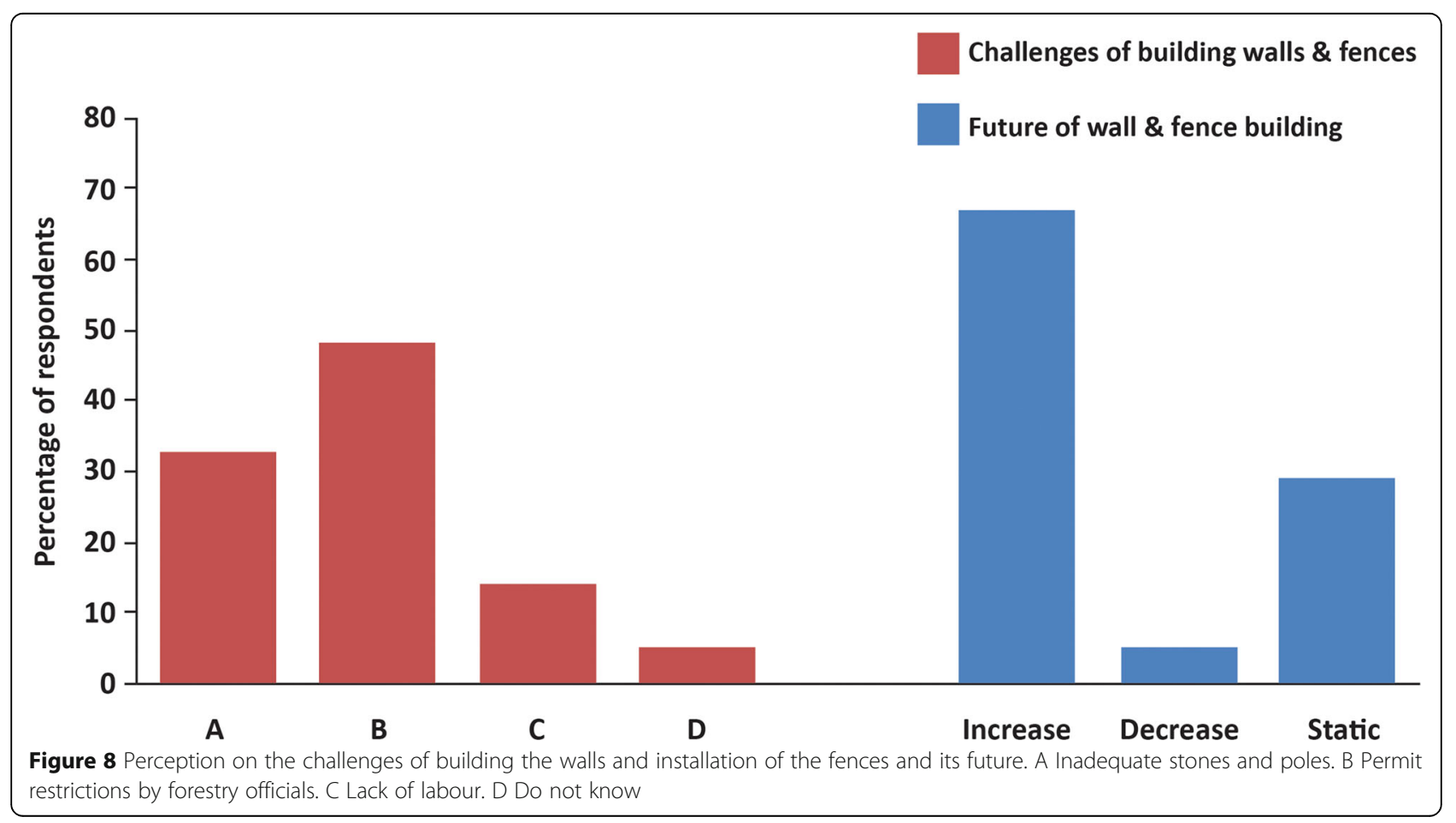


This policy is strategically aimed at centralizing pastoral land resource management in the country. The government has paid cash compensation (Palden 2016; NLC 2007) to most of the other tsamdro holders but have not yet compensated the Brokpas. As a result of nationalization, the Brokpas' resilience in preserving their unique cultural landscapes may be transformed over time. However, the Brokpas still continue to protect their tsamdro rights as before, and they badger the authorities to reverse the nationalization decision. Despite the change in policies and reluctance among Brokpas to surrender their tsamdro, the government's planning and policy development must be grounded in Brokpas' livelihood experience and knowledge to ensure sustainable highland developments. Currently, the pastureland nationalization is still in a transitional phase, and it is too early to speculate about the policy's long-term consequences.

The majority of respondents $(67 \% ; n=14)$ would like to construct more tsamdro border structures in the future (Figure 8). Despite the change in the government's policy on tsamdro ownership, theBrokpas still continue to build new stone and wooden fences to protect their livelihood. In this perspective, the mainstream policies, particularly the Land Act 2007 and the Forest and Nature Conservation Act 1995, contradict the actual tsamdro grazing practice by the Brokpas. The contradiction between policy and practice generates conflict of interest between the policy-makers and the Brokpas. This contradiction also has created an unnecessary dilemma and confusion among the highlanders and most importantly, it will have a detrimental effect both on the social harmony of nomadic herders and the traditional tsamdro management practice.

The contradiction between the policy and practice further questions whether nationalization is a panacea for the correction of inequality between tsamdro resource accessibility in the country. Though the Brokpa population is insignificant, the implementation of these policies posed a considerable threat to their livelihood, when they are already under increasing pressure from shrinkage of grassland, climate change and diseases (Wangda 2016; Wangchuk et al. 2013a, 2013b).

However, during the recent first ever consultative workshop with more than 353 highlanders from ten districts, the government proposed the Highland Development programme as one of the flagship programmes for the 12th Five Year Plan (MOAF 2017), that may bring socioeconomic developments within the Brokpa society. Such consultations would enable the government to bridge a gap between policy and practice. Most importantly, socioeconomic development incentives are required to address the inequalities in tsamdro resource access, poor management of tsamdro practised for hundreds of years, while also to minimize grazing conflicts among the herders.

\section{Conclusions}

Yak herding is and will continue to be a reliable resource of livelihoods for brokpas, and the tsamdro will play a significant role in shaping the socio-economic developments of highlanders in Bhutan. For centuries, dry-stack stone walls and wooden fences have been used to restrain livestock, protect grazing meadows from other animal intruders and indicate tsamdro boundary lines. Though tsamdro border structures were never built directly with an objective to manage tsamdro, they seem to have played an indirect role in tsamdro management practices. Consequently, these structures have not only ameliorated the living conditions of brokpas but also reduced grazing conflicts and ensured social harmony.

The Land Act 2007 has posed a significant challenge by inviting various pastureland-related laws and rules to be applied retrospectively, such as the restrictions imposed by government forestry officials on building new or renovating existing border structures. The changes brought by these policies will have a detrimental effect on both the social harmony of nomadic herders and the traditional tsamdro management practice, which may or may not be addressed by the current tsamdro lease system. However, it is too early to speculate about the likely impact of these policies on the cultural landscapes of brokpas.

Despite the change in policies, the brokpas still continue to build new walls and fences whenever deemed necessary to protect their livelihoods. This contradiction between the mainstream policy and the actual pastureland utilization practice is undermining the value and daily livelihood arrangements of highlanders. The government must bridge the policy worlds and daily life of brokpas to ensure sustainable developments. We recommend that policymakers develop an innovative tsamdro resource-sharing mechanism such as collaboration of brokpa communities to address the grazing conflicts among herders. Socio-economic development incentives are required to address the inequalities of tsamdro resource access and the illegal grazing conflicts.

\section{Endnotes}

${ }^{1}$ Hybrid male and female progeny of yak bull and cattle

\footnotetext{
Acknowledgements

The authors are grateful to the Park Manager of Sakteng Wildlife Sanctuary and his staff, particularly the Merak and Sakteng range's staff for their assistance in the data collection. We would like to express our gratitude to UWICER for funding the study. Our deepest gratitude to the UWICER research assistants for their support in the data collection; Mr. Tshering Dhendup, UWICER, for contributing his photograph taken during the fieldwork and Mr. Sangay Pelzang for his help in preparing the study site and boundary maps. We also would like to extend heartfelt thanks to all the participants of Merak and Sakteng gewogs and reviewers for providing their comments and suggestions.
} 


\section{Authors' contributions}

SW and NN carried out the fieldwork and data analysis. SW drafted most parts of the manuscript, while NN significantly contributed by providing critical feedbacks and guidance throughout the research process. Both authors read and approved the final manuscript.

\section{Authors' information}

SW is the head librarian of the Ugyen Wangchuck Institute for Conservation and Environmental Research and also a founding member of the Bhutan Library Consortium. Apart from his profession, he undertakes research in the field of social science at the Institute. NN is a director of the Ugyen Wangchuck Institute for Conservation and Environmental Research under the Ministry of Agriculture and Forestry Services. He received his Ph.D. from the Max Planck Institute of Germany for his research on the movement ecology of altitudinal migrants in high-altitude birds and mammals.

\section{Competing interests}

The authors declare they have no competing interests.

\section{Publisher's Note}

Springer Nature remains neutral with regard to jurisdictional claims in published maps and institutional affiliations.

Received: 13 July 2017 Accepted: 5 November 2017

Published online: 31 January 2018

\section{References}

Bagchi, S., C. Mishra, and Y.V. Bhatnagar. 2004. Conflicts between traditional pastoralism and conservation of Himalayan ibex (Capra sibirica) in the TransHimalayan Mountains. Animal Conservation 7 (2): 121-128. https://doi.org/10. 1017/S1367943003001148

Blench, R. 2001. ' You Can't Go Home Again' pastoralism in the new millennium. Food and Agriculture Organization of the United Nations, May 2001: 1-106.

Chand, R. 2017. Brokpa yak herders of Bhutan: A study in pastoral livelihood patterns, transhumance and 'Drukor'. In Societies, Social Inequalities and Marginalization, 17997. Springer International Publishing. https:/doi.org/10.1007/978-3-319-50998-3.

Chettri, N. 2008. Local and indigenous practices on adaptation: An experience from herder's life of western Bhutan. Mountain Forum Bulletin 8 (1): 19-21.

Chophyel, P. 2009. Rangeland management in Bhutan. Ministry of Agriculture. Thimphu: Bhutan.

De Haan, C. 1993. An overview of the World Bank's involvement in the pastoral development. United Nations Sudano-Sahelian Office. Paris:World Bank.

Department of Forest (DoF). 2006. Forest and nature conservation rules of Bhutan. Thimphu: Ministry of Agriculture, Royal Government of Bhutan.

Department of Livestock (DoL). 2016. Livestock statistics 2016. Thimphu: Ministry of Agriculture and Forests, Royal Government of Bhutan.

Derville, M., and J. Bonnemaire. 2010. Marginalisation of yak herders in Bhutan: Can public policy generate new stabilities that can support the transformation of their skills and organisations? And bonds to territories: A case study in France and Brazil. Innovation and Sustainable Development in Agriculture and Food 10 (1-12).

Dorji, K. 2013. Rangeland tenure transfer: An analysis of policy and legal issues in Bhutan. Thimphu: The Centre for Bhutan Studies \& GNH Studies, Royal Government of Bhutan.

Fratkin E. and R. Mearns. 2003. Sustainability and Pastoral Livelihoods: Lessons from East African Maasai and Mongolia. Human Organization 62 (2): 112-122.

Gyamtsho, P. 2000. Economy of yak herders. Journal of Bhutan Studies 2 (1): 112-122.

Gyamtsho, P. 2002. Condition and potential for improvement of high altitude rangelands. Journal of Bhutan Studies 7: 82-98.

Gyeltshen T, N Tshering, K Tshering, and S Dorii 2010. Implication of legislative reform under the Land Act of Bhutan, 2007. "a case study on nationalization of Tsamdro \& Sokshing and its associated socioeconomic and environmental consequences". Watershed Management Division, Department of Forest and Park Services, Ministry of Agriculture and Forest, Royal Government of Bhutan: Thimphu

International Fund for Agricultural Development (IFAD). 2009. Livestock and pastoralists. Italy: Livestock Thematic Papers.

Joshi, S.R. 2009. Value chain analysis of dairy in Merak and Sakteng. The Netherlands Development Programme: Ministry of Agriculture and Forests.

Kreutzmann, H. 2012. Pastoral practices in transition: Animal husbandry in high Asian contexts. In Pastoral practices in high Asia: Agency of development effected by moderninsation, resettlement and transformation, ed. Marcus Nusser, 1st ed., 1-29. Berlin: Springer Science+Business media.
Ministry of Agriculture and Forests(MoAF). 2017. Highlanders attends the first ever consultative workshop. http://www.moaf.gov.bt/highlanders-attendsthe-first-ever-consultative-workshop/\#. Accessed 20 October 2017.

Moktan, M.R., L. Norbu, H. Nirola, K. Dukpa, T.B. Rai, and R. Dorji. 2008. Ecological and social aspects of transhumant herding in Bhutan. Mountain Research and Development 28 (1): 41-48. https://doi.org/10.1659/mrd.0802.

Namgay, K., J.E. Millar, and R.S. Black. 2017. Dynamics of grazing rights and their impact on mobile cattle herders in Bhutan. Rangeland Journal 39 (1): 97-104. https://doi.org/10.1071/RJ16052.

Namgay, K, JE Millar, RS Black, and T Samdrup. 2013. Transhumant agropastoralism in Bhutan: Exploring contemporary practices and socio-cultural traditions. Springer, 3 (13): 1-26.

Namgay, K., J.E. Millar, R.S. Black, and T. Samdup. 2014. Changes in transhumant agro-pastoralism in Bhutan: A disappearing livelihood? Human Ecology 42 (5): 779-792. https://doi.org/10.1007/s10745-014-9684-2.

National Land Commission (NLC). 2007. The Land Act of Bhutan. National Land Commission. Thimphu: Bhutan: Royal Government of Bhutan

Ning, W, Y Shaoliang, S Joshi and N Bisht. 2016. Yak on the move: Transboundary challenges and opportunities for yak raising in a changing Hindu Kush Himalayan region, Kathmandu: Nepal. International Centre for Integrated Mountain Development.

Nori, M., and J. Davies. 2007. Change of wind or wind of change? Climate change, adaptation and pastoralism. Nairobi: IUCN.

Palden, T. 2016. Tsamdro compensation set to begin this month—KuenselOnline. Kuensel, January 1. http://www.kuenselonline.com/tsamdro-compensationset-to-begin-this-month/. Accessed 23 December 2016.

Ura, K. 1993. The nomads' gamble pastoralists of northern Bhutan. South Asia Research 13 (2): 81-100. https://doi.org/10.1177/026272809301300201.

Ura, K. 2002. The herdsmen's dilemma. Journal of Bhutan Studies, 7:1-43. Thimphu: Centre for Bhutan Studies \& GNH Research, Bhutan.

Wangchuk, D., W. Dhammasaccakarn, P. Tepsing, and P.N.S. Thongphon. 2013. The yaks: Heart and soul of the Himalayan tribes of Bhutan. Journal of Environmental Research and Management 4 (2): 189-196.

Wangchuk, K., T. Gyaltshen, T. Yonten, H. Nirola, and N. Tshering. 2013. Shrubland or pasture? Restoration of degraded meadows in the mountains of Bhutan. Mountain Research and Development 33 (2): 161-169. https://doi.org/10.1659/ mrd-journal-d-12-00091.1.

Wangchuk, K., M. Wurzinger, A. Darabant, G. Gratzer, and W. Zollitsch. 2014. The changing face of cattle raising and forest grazing in the Bhutan Himalaya. Mountain Research and Development 34 (2): 131-138. https://doi.org/10.1659/ MRD-JOURNAL-D-13-00021.1.

Wangda, P. 2016. Yaks and yak herding: Challenges and opportunities in the Bhutanese Himalayas. In Yak on the Move: Transboundary Challenges and Opportunities for Yak Raising in a Changing Hindu Kush Himalayan Region, edited by Wu Ning et al., 65-76. Kathmandu: International Centre for Integrated Mountain Development, Nepal.

Wangdi, J. 2016. The future of yak farming in Bhutan: Policy measures government should adopt. The Rangeland Journal 38: 367-371.

Wiener, G, H Jianlin, and L Ruijun, ed. 2003. The yak. Second edition. Bangkok: Food and Agriculture Organization of the United Nations.

Wildlife Conservation Division Assessment (WCD). 2013. Assessment on impact of human-wildlife conflict management intervention to the local communities. Department of Forests and Parks, Ministry of Agriculture and Forests. Thimphu: Department of Forests and Parks, Royal Government of Bhutan.

\section{Submit your manuscript to a SpringerOpen ${ }^{\mathcal{O}}$ journal and benefit from:}

- Convenient online submission

Rigorous peer review

- Open access: articles freely available online

- High visibility within the field

- Retaining the copyright to your article

Submit your next manuscript at $>$ springeropen.com 